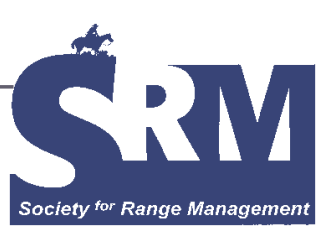

\title{
Oh! How I Miss Those Great North Dakota Nights!
}

\section{By Hannah Frieling}

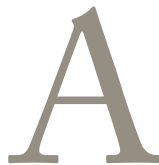

s I walk on this nature walk, I don't see much of the true meaning of nature. Sure, there are some trees; I see the sky and some grass. That truly isn't nature. What I see more of is gum stuck to the ground and trash everywhere. I look up into the great blue sky, but I really don't see the great blue sky, I see black smoke from all of the pollution. The cars travel on like there is nothing wrong, but it is ruining the true meaning of life. When humans first started out, they had none of the things we have that we use in our everyday life. We let technology take over. Why do we take nature for granted? It is such a beautiful thing.

While I was walking along, seeing all of the garbage, I was thinking of the great summers that I have had in North Dakota with my stepdad's family. They live on a farm, in what seems like the middle of nowhere. There are no neighbors for at least 2 miles. You can walk around freely, just enjoying the fresh air that is truly fresh and doesn't have all of the black smoke that we breathe everyday. While you walk, you don't have to look at garbage that people throw on the ground because they are just too lazy to put it in a trash can. Everyone is taking nature, our home, for granted nowadays.

When I look up into the sky at night here, I see a few stars once in awhile. The summer nights in North Dakota though, well I have one word, and it's WOW! I loved looking up into the night sky, staring at the beautiful stars. It was absolutely breathtaking. I had no worries, just thinking how something so beautiful couldn't be seen where I live. While I am in North Dakota, I do sometimes take it for granted, and I admit it. Right now, though, while I look back on it, I think it was one of the most relaxing times of my life.

As I walked through the Bog, I noticed some tree stumps. The trees were cut down for electrical uses. Why would anyone cut down something as grand as a tree, and for all reasons, electrical uses? We are always depending on technology nowadays. What if one day it all disappears? We would surely regret cutting down trees just so we can make way for electrical wires.

Now I sit here, and I wonder why we rely on technology. Is it because we grew up with it and have always had it at our feet? Once in awhile though, everyone should just take a break, breathe. Go somewhere special with little or no technical things. Look up at the sky and think, why do we let our lives revolve around technology and take the beautiful nature for granted?

Editor's Note: The author wrote this paper as an assignment for her ninth grade Classical Literature Class at Thornton High School, Thornton, Colorado.

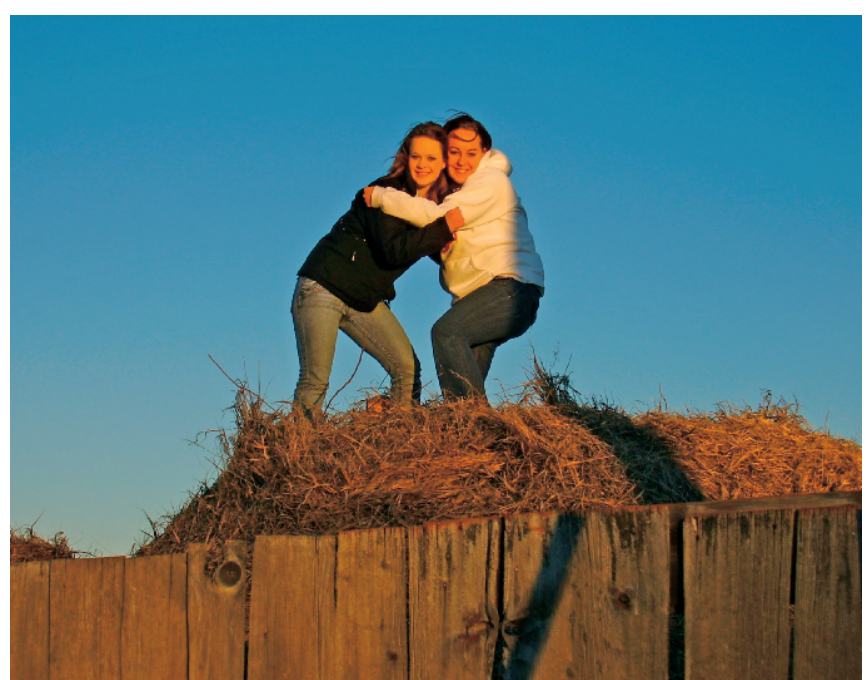

The author (Hannah) on the right and her stepsister, Markita, on a haystack in North Dakota, under the stars. 